\title{
Teachers in Industry: Measuring the Impact of a K-12 Teacher Internship Program
}

Introduction

The importance of STEM learning is becoming common knowledge across the educational community. Although many people will have different opinions about what true STEM learning is, most everyone will agree that making the classroom content relevant for students is a critical component. ${ }^{1,2,10,11}$ This also involves incorporating specific delivery techniques such as hands-on learning and inquiry-based instruction. Teachers are also continuously challenged with developing classroom activities that are engaging for students and involve an authentic component to real-world contexts. ${ }^{2}$ For many teachers this can be a challenge, since most teachers that have earned a teaching license through traditional methods do not have corporate work experience. Therefore, having the knowledge about how industry is currently using different processes to solve technological problems may not be familiar to most teachers. By giving teachers an opportunity to work in a corporate environment as part of an internship program, they can bring valuable knowledge back to the classroom. $1,3,4,5,6,7,8$ This can be new knowledge about the engineering design process (EDP), 21st century skills, team collaboration, global communication, problem-solving, critical-thinking, or many other types of skills needed to be successful in the workplace. Being able to increase student engagement through the use of these authentic skills will help better equip them for the future. ${ }^{8,9}$ Therefore, if teachers are to be challenged to train the future workforce, they need to have an understanding of how the current workforce operates.

\section{Background}

The idea of teacher internships is not new and there have been several programs for teachers to gain corporate work experience as a professional development opportunity. Two of the most popular externally funded programs for teachers to gain industry and research experience are Scientific Work Experience Programs for Teachers (SWEPT) and Research Experiences for Teachers (RET). ${ }^{3,4,12}$ The goals for these programs are to increase the teacher's understanding of how content knowledge is being applied in an authentic real-world setting in order to increase students engagement and achievement in the classroom through implementation of an authentic educational plan. Some research studies show these types of experiences for teachers have led to an increase in student achievement for their respective students in science ${ }^{5}$, however the documentation for this type of research is limited. Both of these programs provide unique opportunities in different settings. The SWEPT programs typically place teachers in an industry environment while RET programs place teachers in an on-campus research facility.

There are also many programs being implemented regionally that place teachers in a corporate work environment. The Industry Initiatives for Science and Math Education (IISME) is a popular program located in California. ${ }^{1}$ Initiated in 1985, this program places teachers in STEM related fields into industry positions for 8-week summer work experiences. Once the experience is complete, the teachers are required to produce an Education Transfer Plan for integrating the knowledge gained through the work experience into the classroom. ${ }^{1,4}$ The Georgia Intern 
Fellowships for Teachers (GIFT) program is sponsored by the Georgia Institute of Technology through its Center for Education Integrating Science, Mathematics, and Computing. ${ }^{6}$ Since 1991, this program has placed an average of 75 teachers per year in university and industry settings to gain practical knowledge about current industry practices. ${ }^{6}$ Program evaluations on both the IISME and GIFT program reveals that after participating, classroom teachers are more likely to use "real-life" examples, incorporate hands-on activities, integrate other fields of knowledge within their course curriculum, and use scientific inquiry as a methods of problem, investigation and solution development. ${ }^{3,4}$ It has also been shown that participating teachers have a higher retention rate than teachers who do not participate. ${ }^{1,6}$ These are just two examples of the many opportunities being offered nationwide in an attempt to empower teachers with additional skills to authenticate course material in the classroom, but the evidence is clear that teacher internships are a valuable program for teacher professional development.

\section{Current Project}

The current research project evaluates a teacher internship program developed at North Dakota State University in the community of Fargo, North Dakota and Moorhead, Minnesota. The goal of the research project is to determine if the Teachers in Industry: K-12 Teacher Internship is a an effective educational professional development program by changing a teacher's classroom practices in regards to using the EDP to more effectively to deliver classroom content. The research questions for this project are as follows:

1. Does the Teachers in Industry: K-12 Teacher Internship program change teachers' perceptions of how the EDP, 21st century skills, collaboration, and project-based learning can be used to change classroom practices to deliver course content more effectively?

2. Does the Teachers in Industry: K-12 Teacher Internship program change teachers' perceptions of how knowledge of current industry practices in a technological environment can effectively be used to make course content more relevant for their students?

\section{Teachers in Industry Program Description}

As previously discussed, teachers are continuously being challenged to increase student achievement, engagement, and prepare them for the future workforce. ${ }^{1,2}$ The current program discussed in this paper was developed to meet a growing need in the community. The Teachers in Industry program has been designed through a review of the best practices of other teacher internship programs.

The Teachers in Industry program components are as follows:

1. The program begins with an application process. Since there are fewer available corporate positions than the number of interested teachers, a selection process is required. The application collects basic contact information as well as two short answer questions to gauge the teacher's interest in not only participating in the work experience, but how this experience could potentially transform their classroom teaching practices. Once the initial applications are reviewed, the selected teachers are interviewed. The interview consists of the internship 
coordinator from North Dakota State University, a member of the Greater Fargo-Moorhead Economic Development Corporation, and human resource representatives from the participating companies. The behavior-based interview structure is designed to gauge which teachers will benefit most from the program and will have the greatest impact on their students when returning to the classroom.

2. Enrollment in the EDUC 600: K-12 Teacher Internship course through the Distance and Continuing Education office at North Dakota State University. Once the course requirements are complete, the teacher will receive three continuing education credits towards license renewal. The course requirements are as follows:

- The teacher works for four weeks, approximately 30 hours per week, Monday through Thursday, for a engineering or design-focused corporation. During this time, the teacher is exposed to all the different steps of the EDP and how these processes are used to solve technological challenges in a global environment. The unique aspect of this program is the type of exposure the teacher receives in regards to all the different processes of the corporation. The teacher does not perform the same task throughout the work experience. The teacher is given an overall project to develop which requires short term deliverables to accomplish as they move through different departments within the corporation. With the assistance of an internship coordinator assigned by the company, the teacher's time is coordinated in order that they may be exposed to as many different steps of the EDP as possible during the work experience. This allows to teacher to observe many different projects that are in vary stages of their development. In addition, the teacher completes the new employee training, gains access to appropriate email and server files, and participates in any other activities deemed critical to a fully immersive experience. Once the work experience is complete, the teachers receive a $\$ 2,000$ stipend, half of which is paid by the company and the other half is paid for by the local regional education association (REA).

- Each week, the teacher participants must submit a weekly written reflection. This assignment gives the teachers an opportunity to reflect on what they learned during the week and how it will help them become a more effective teacher. It also provides documentation of their experience that can be included in their final portfolio.

- Every Friday during the 4-week program, all the teachers participating in the program meet together along with the internship coordinator to discuss the previous week's experiences. This is an extremely critical component of the program that allows the teachers not only to share, reflect, and learn from their own experiences, but to hear the experiences from the other teachers. Since each company uses the EDP in different ways, it is extremely beneficial for the teachers to be able to share the different experiences of the week. During this time, the discussion focuses on how this knew knowledge can be translated into the classroom to increase student engagement, the relevance of activities, improved classroom management, and developing effective project-based learning activities.

- Each teacher is required to develop a lesson plan portfolio. This lesson plan is designed around the new knowledge gained throughout the work experience and has been proven to be a critical component of internship experience. ${ }^{1}$ The portfolio is due several weeks after the conclusion of the internship in order to allow the teacher time to reflect and incorporate all the new knowledge gained during the experience. The portfolio must be submitted "implementation-ready". The intent is to build a database of lesson plans 
developed through the internship experience that can be shared with colleagues to provide classroom-ready materials designed to be delivered through a STEM-learning platform. The teachers are required to incorporate two different aspects within the lesson plan design.

a. The teacher must use new knowledge gained about the EDP and 21st century skills within the delivery of the lesson plan. The lesson must be implemented in a new manner that models how the corporation uses processes to solve technological problems.

b. The teacher must use information specific to the companies products and infrastructure when design the content. The teacher must find a way to incorporate information about the company's products and use this information to authenticate the real-world application of the curriculum content.

- Once the work experience and lesson plan are submitted, the teacher receives an incomplete for the course. To have the incomplete changed to a passing grade, the teacher must implement the lesson plan the following semester. Once the lesson plan has been implemented, the teacher must analyze the lesson plan design and delivery, revise it as necessary based on reflective practice, and resubmit the lesson plan to the internship coordinator. Once the resubmission is complete, the teacher's grade will be changed to a passing mark.

\section{Example Projects}

The following are descriptions of some typical projects for which the teacher may be responsible during the work experience.

\section{Process Capability Project}

Process capability is an important deliverable within an organization's design process. Project teams are challenged to better understand process capabilities and how it drives decreased ramp up time into full production. The intern would analyze a project by reviewing past equipment ramp-up quantities and compare these with the associated process capability values. The project deliverable would be to understand the correlation and business impacts of a capable process versus a process still in infancy.

\section{Design for Manufacture \& Assembly (DFMA) Metric Project}

DFMA metrics are becoming more useful during regular team interaction. Metrics, such as number of parts, number of part numbers, bends, and lengths of welds, feed into overall cost and productivity targets. Keeping a close eye on the driving metrics enables the company to better understand what the design is ultimately going to deliver. Unfortunately, these drivers are typically hard to gather and take significant team member time to compile. The intern would work to better understand tool design and how they are used by manufacturing engineers and provide suggestions for improving the standard of work.

\section{Workflow Improvements}

Many large healthcare facilities need to constantly analyze the flow of work throughout the facility. This can include operations such as improving patient experience, work-flow design, and surgical team efficiency. The intern can work within the office of continuous improvement 
to study how patients are admitted, serviced, and discharged in order to reduce patient wait time. This will include analyzing patient, nurse, doctor, and administration flow of personnel and documentation throughout the process. Recommendations can be made on a micro-level for improving the processes.

\section{Research Methodology}

The current research project is designed to analyze the effectiveness of the Teachers in Industry program. This includes studying the effects on the teacher's perceptions and knowledge of the EDP and 21st century skills, and how the internship experience translates to improving teaching practices. The study is a compilation of data collected over the past two years. During this time, five teachers have participated in the internship program. The first year, one teacher was chosen to ensure the internship program was organized properly and the logistics of the program were coordinated appropriately for the host company. The following year, four teachers participated. Although the title of the program is designated as $\mathrm{K}-12$, for first two years of the program were only available to teachers in grades 6-12. The name was chosen to prepare for the future participation of elementary teachers, which will be available beginning the summer of 2013. Table 1 describes the participants of the internship program for the summers of 2011 and 2012.

Table 1

Teacher Demographics

\begin{tabular}{|c|c|c|c|}
\hline Teacher & Gender & Grade & Subject \\
\hline 1 & Female & 7 & Mathematics \\
\hline 2 & Male & 7 & Social Science \\
\hline 3 & Male & 8 & STEM, Technology Education \\
\hline 4 & Female & 9 & Geography \\
\hline 5 & Male & 10 & Biology \\
\hline
\end{tabular}

The quantitative data was collected using a survey given before and after the internship program. The survey is an exploratory instrument with is in the process of being analyzed for validity and reliability. It was designed with 11 questions which could be grouped together by the researcher to gain the teacher's perception of their understanding of the following topics: EDP, 21st century skills, collaboration, and project-based learning. The survey provided information to the researcher that would allow for a basic statistical analysis to verify the significance of the program, compare it to the program goals and outcomes, and determine if it has an impact of the teacher's perceptions of the Engineering design process and classroom teaching practices. The survey questions were based on information researched about the GIFT program from the Georgia Institute of Technology. ${ }^{3}$ Although the data is antidotal in nature, it provides valuable insight to the importance of internship programs and particularly the Teachers in Industry 
program. The survey questions were presented as a Likert scale to determine if the teachers believed there was value within the program and to what affect it will change their teaching practices. The average Likert score for each question was calculated. Using SPSS, a t-test was performed between the average scores of the pre-survey and post-survey results. In addition, a similar test was conducted on the groups of questions to determine how the internship affected a specific topic.

The qualitative component was in the form of interviews. Interviews were conducted with each participant before and after the work experience to gain a deeper understanding of how the internship program will affect the teacher's classroom practices. The interviews were semistructured, which allowed the researcher to ask questions that would provide deeper understanding of the responses given by the teacher.

Survey Results

Table 2

Descriptive Results of All Survey Questions (based on Likert Scale Values)

\begin{tabular}{|c|c|c|c|c|}
\hline Question \# & Survey Question & Pre-Survey & Post-Survey & $\Delta$ \\
\hline 1 & I understand the engineering design process & 4.2 & 4.6 & 0.4 \\
\hline 2 & $\begin{array}{l}\text { I know how to incorporate } 21 \text { st century skills } \\
\text { into my lesson plans }\end{array}$ & 3.6 & 4.4 & 0.8 \\
\hline 3 & $\begin{array}{l}\text { I know how to make my content relevant to } \\
\text { the real world for my students }\end{array}$ & 4.2 & 4.4 & 0.2 \\
\hline 4 & $\begin{array}{l}\text { It is important to incorporate } 21 \text { st century } \\
\text { skills into lesson plans }\end{array}$ & 5.0 & 5.0 & 0.0 \\
\hline 5 & I incorporate the EDP into lesson plans & 3.6 & 4.8 & 1.2 \\
\hline 6 & $\begin{array}{l}\text { I use hands-on projects in the classroom to } \\
\text { teach my content }\end{array}$ & 4.0 & 4.6 & 0.6 \\
\hline 7 & $\begin{array}{l}\text { I feel comfortable designing a hands-on } \\
\text { project-based activity to teach my content }\end{array}$ & 3.8 & 4.6 & 0.8 \\
\hline 8 & $\begin{array}{l}\text { I know how to assess } 21 \text { st century skills in the } \\
\text { classroom }\end{array}$ & 3.2 & 4.0 & 0.8 \\
\hline 9 & $\begin{array}{l}\text { Understanding how the EDP is used in a } \\
\text { cortporate environemnt will help me become a } \\
\text { more effective teacher }\end{array}$ & 4.6 & 4.8 & 0.2 \\
\hline 10 & $\begin{array}{l}\text { I collaborate with teachers in my same content } \\
\text { area at school }\end{array}$ & 3.8 & 4.4 & 0.6 \\
\hline 11 & $\begin{array}{l}\text { I collaborate with teachers in different content } \\
\text { areas at school }\end{array}$ & 4.0 & 4.6 & 0.6 \\
\hline
\end{tabular}

Likert Scale: 1 = strongly disagree, $2=$ disagree, $3=$ neutral, $4=$ agree, $5=$ strongly agree 
The descriptive results for all of the survey questions are shown in Table 2. When analyzing the survey results, the greatest gain in a survey score was question number five. The result to this question demonstrates the teachers perceive it is important to design lesson plans and deliver course content in a manner that incorporates the EDP. The descriptive results for the four different groups of the survey questions are shown in Table 3.

Table 3

Descriptive Results of Survey Questions by Group (based on Likert Scale Values)

\begin{tabular}{|c|c|c|c|c|}
\hline Group & Survey Questions & Pre-Survey & Post-Survey & $\Delta$ \\
\hline All Questions Combined & & 4.00 & 4.56 & 0.56 \\
\hline EDP & $1,5,9$ & 4.13 & 4.73 & 0.60 \\
\hline 21st Century Skills & $2,4,8$ & 3.93 & 4.47 & 0.54 \\
\hline Collaboration & 10,11 & 3.90 & 4.50 & 0.60 \\
\hline Project-Based Learning & $3,6,7$ & 4.00 & 4.53 & 0.53 \\
\hline
\end{tabular}

Likert Scale: 1 = strongly disagree, $2=$ disagree, $3=$ neutral, 4 = agree, $5=$ strongly agree

Table 4

Statistical Results for Survey Questions

\begin{tabular}{|c|c|c|c|c|c|}
\hline Questions & Survey & $\mathrm{N}$ & Mean & Std. Dev. & $\mathrm{P}$-value \\
\hline \multirow[t]{2}{*}{ All Questions Combined } & Pre & 5 & 4.00 & 0.475 & $0.003 *$ \\
\hline & Post & 5 & 4.56 & 0.253 & \\
\hline \multirow[t]{2}{*}{ EDP } & Pre & 5 & 4.13 & 0.411 & 0.114 \\
\hline & Post & 5 & 4.73 & 0.094 & \\
\hline \multirow[t]{2}{*}{ 21st Century Skills } & Pre & 5 & 3.93 & 0.772 & 0.437 \\
\hline & Post & 5 & 4.47 & 0.411 & \\
\hline \multirow[t]{2}{*}{ Collaboration } & Pre & 5 & 3.90 & 0.100 & 0.051 \\
\hline & Post & 5 & 4.50 & 0.100 & \\
\hline \multirow[t]{2}{*}{ Project-Based Learning } & Pre & 5 & 4.00 & 0.163 & $0.016^{*}$ \\
\hline & Post & 5 & 4.53 & 0.094 & \\
\hline
\end{tabular}

*significant at $\alpha=0.05$ 
The results show a gain in the average of all the survey questions as well as the four groups within the survey. This demonstrates the value of the program in regards to how the teachers perceived the benefit of the internship and how their understanding and perception of the importance of these topics was increased.

The statistical results for the t-test analyses for all of the survey questions combined as well as the four groups are shown in Table 4. The statistical analysis demonstrates there was a statistically significant difference in survey results when combining all the survey questions. The participating teachers' perceptions of the internship program was that it benefitted them in learning the importance of incorporating the EDP into their classroom practices and how it would be beneficial for preparing lesson plans and delivering course content. The one separate category that was statistically significant is the topic of project-based learning. The teachers felt the work experience showed them the importance of using authentic hands-on projects in the classroom as a method of delivering course content and demonstrating an understanding of concepts. The small number of participants is a limiting factor in the qualitative analysis. The researcher has designed the study so that it will increase in power as the number of internships and teacher participants increase. Therefore, the researcher has included a qualitative component to further support the results of the quantitative analysis.

\section{Interview Results}

To gain a deeper understanding of the teachers' perceptions of the internship program, the researcher conducted semi-structured interviews with the participants. The following descriptions summarize the responses in regards to how the internship affected the teachers' knowledge and perceptions about the EDP, 21st century skills, collaboration, and project-based learning.

\section{Engineering Design Process}

Before the internship, one teacher did not know a lot about the EDP. They had heard of it but had never been exposed to the steps or how it is implemented; "I have heard of it, and teachers at other schools use it, but that's about all I know." Another teacher said, "I know a little bit, I just basically know the steps. But not real in-depth". Another teacher said, "I basically know the steps and know that it's related to the scientific method". Two teachers knew a lot about the EDP. Through, the interview, it was apparent they had experience implementing the EDP in the classroom and assessing students on thee skills. These teachers consistently implemented EDP concepts into their lesson plans and created engaging environments for the students.

After the internship, all the teachers said they gained a tremendous amount of knowledge about the EDP. The three teachers with very little knowledge of the EDP before the internship felt overwhelmed at how much goes on in a corporate environment. Some of these comments were, "I was able to see the bigger picture of how they used the EDP to solve problems, and I saw every step along the way in some form. Some of this was on smaller projects on a daily basis and some were on long term projects on a larger scale". Another teacher, when asked how much they learned about the EDP, said, "I learned a ton. I didn't even know the steps before I started. To 
learn the steps and see them in action at the same time was really beneficial to me". The two teachers with previous experience with the EDP said they saw many different ways the EDP is being used that they had not been exposed to or have previously thought of. One of them said, "Even though I knew a lot about the EDP, I had the chance to see it being applied in a real world context". Another comment was, "I learned a lot about applying the EDP, and I think when it comes down to how I'm going to take that into the classroom, I'm going to look at the tools I gained from this and how this could be so much better if everyone on the teaching team knew how things were done in the real world".

\section{1st Century Skills}

Before the internship, most teachers agreed that 21 st century skills are important, however three of the five teachers defined 21st century skills simply as using computers or technology. Four of the teachers agreed 21 st century skills were important for students to know, but none of them could explain how they specifically taught or assessed these skills in the classroom. The other teacher said, "These skills [21st century skills], may be important, but they are not as important as teaching the content knowledge". One teacher said, "I feel like I need more training to implement and assess 21st century skills". Another comment was, "I know some of the buzz words, but I don't know a whole lot about 21st century skills". Another teacher stated that even though they have heard of 21 st century skills, they could not give a definition or describe what they thought 21 st century skills are.

After the internship, all of the teachers admitted the definition and use of 21st century skills changed throughout the work experience. One teacher said, "I learned 21 st century skills are more than just computers. It includes communicating, working and collaborating with others, problem-solving and critical thinking". Another teacher said, "I had no idea how important these skills were in the current workforce. Team members were collaborating and communicating all the time and I was amazed as how the different dynamics of the group were used to solve problems."

\section{Collaboration}

Before the internship, three of the five teachers felt that collaborating with teachers from other subjects was not as important as collaborating with teachers in their own subject. They did not take time to seek out collaborations with teachers in other subjects nor were they proactive about collaborating with teachers in their own subject. Two of the teachers regularly met with teachers from other subjects to design lessons. One teacher said, "Collaborating with teachers in our own subject works well because we have the same planning period and our classrooms are next to each other. But we don't get a chance to collaborate with teachers in other content areas".

After the internship, all the teachers agreed that the importance of interdisciplinary collaboration increased. Experiencing first-hand collaboration from the work experience changed their attitude about the need for collaboration. One teacher commented, "I don't have enough time to collaborate with teachers from other subjects, but it is more important than I previously thought".

\section{Project-Based Learning}

Before the internship, all the teachers mentioned they tried to insert hands-on activities through real-world examples into their lessons, but struggle with finding different examples and how to 
make them engaging for the students. "I try to incorporate hands-on activities so the students aren't just getting facts, but are being introduced to what is going on in the real-world. But it is difficult to come up with new ideas on a consistent basis". The teacher then goes on to say, "I would like to use them more often and would like more examples of how to do that". Another teacher said, "We try and create authentic opportunities for our students, although this is not always an easy thing to do". Whenever asked about how they implement PBL activities in the classroom, most teachers stated they used computers as the largest component of the PBL activities.

After the internship, when asked about the value of PBL activities, one teacher responded, "I learned they [PBL activities] connect the hand and mind and cements the learning process. I can cover material in the classroom and move on, or I can give them an experience that will stick with them." Another teacher said, "I think using more PBL activities will keep more students engaged in the material." Another teacher says, "I think students will enjoy them [PBL activities] more". All the teachers felt they gained more of an appreciation for the importance of using hands-on PBL activities in the classroom. They all knew it was important to include hands-on learning in the classroom, but now they see it as a critical component.

\section{Overall Impact}

Overall, the teachers felt the program was very worthwhile. The particular areas of increased knowledge include how the EDP is used in a corporate environment to solve technological problems and how diverse groups of employees collaborate to solve varying challenges in a local and global environment. All of the teachers said that probably the most significant benefit was seeing how what they taught in the classroom is being used in the real-world. It allows them to tell their students about actual experiences that relate content knowledge to authentic contexts. Some closing comments from the teachers include, "It [the teacher internship] really opened my mind to different ideas and concepts", "It's really important to see the bigger picture and using experiences to teach rather than producing canned lessons", "I truly see the value in stepping outside of my comfort zone and trying something new [referring to lesson plan delivery] and take a risk on some new ideas I have, because I have seen the value in it", "I learned that the problem solving process can be messy, but that's okay as long as you get the solution you are looking for". The general theme from the all of the interview responses was the internship program was a valued experience for each of the teachers. One teacher even asked if they would be able to do it again.

\section{Discussion}

The quantitative analysis shows a significant increase in the overall perception of the benefit of the Teachers in Industry: K-12 Teacher Internship program. This is indicated by the statistical significance in the pre and post-survey questions for all the survey questions. In addition, the teachers thought the work experience was especially beneficial for understanding the importance of project-based learning. The qualitative analysis gave the researcher an opportunity report some specific comments and trends experienced from the teacher interviews. Although each 
teacher seem to gain different specific insights from the work experience, each teacher reported some detailed responses and examples of ways the internship will benefit their classroom practices.

Teacher internships are an important component to the educational community. By allowing teachers to gain first-hand experience of how corporations are using complex processes to solve technological problems, the classroom experience for the students could be much more rewarding. Very little research documents the actual gain in achievement by students of teachers who have participated in these programs, which is the next step in this researcher's plan. However, much data exist that shows and increase in the teachers' perception of the importance of incorporating industry practices into the classroom. This research study demonstrates that the Teachers in Industry: K-12 Teacher Internship program has a value-added component to the educational community. Not only does it benefit the teachers, but it builds a relationship between industry and the educational community that is vital to the development of quality educational programs. This is reflected in how the teachers feel about how the program makes the classroom experiences, lesson plan designs, and content delivery more engaging for the students. It also allows teachers to incorporate authentic project ideas learned from their experience as well as from the other teachers participating in the program.

\section{References}

1. Industry Initiatives for Science and Math Education (2013). http://iisme.org/

2. Partnership for 21st Century Skills. (2011). Professional Development: A 21st Century Skills Implementation Guide. http://p21.org/storage/documents/p21-stateimp_professional development.pdf

3. Barrett, D. \& Usselman, M. (2006). Assessing the Long Term Impacts of Scientific Work Experience Programs for Teachers. Annual Proceedings of the American Society for Engineering Education, Chicago, IL.

4. Barrett, D. \& Usselman, M. (2005). Experience to Impact: A Comparison of Models of University-Based Summer Internships for High School Teachers. Annual Proceedings of the American Society for Engineering Education, Portland, OR.

5. Silverstein, S., Dubner, J., Miller, J., Glied, S. \& Loike, J. (2009). Teachers' Participation in Research Programs Improves Their Students' Achievement in Science. Science, Vol. 326. P. 440-442.

6. Center for Education Integrating Science, Mathematics, and Computing (2012). Georgia Intern Fellowships for Teachers. https://www.ceismc.gatech.edu/gift/

7. Farrell, A. M. (March, 1992). What Teachers Can Learn from Industry Internships. Educational Leadership.

8. Center for Digital Education (2013). http://www.centerdigitaled.com/stem/STEM-Teachers-Excel-IndustryInternships.html

9. California Polytechnic College of Science and Mathematics (2012). STAR Program, http://starteacherresearcher.org/about.html

10. Newman, F., Marks, H. \& Gamoran, A. (1996). Authentic pedagogy and student performance. American Journal of Education, 104(4), 280-312.

11. Stepien, W. \& Gallagher, S. (1993). Problem-based learning: As authentic as it gets. Educational Leadership, 50(7), 25-28.

12. Triangle Coalition for Science and Technology Education (2013). http://www.trianglecoalition.org/ 